\title{
Un análisis lingüístico de los ideófonos coreanos en un fragmento de un cuento de Park Min-Gyu
}

\section{A Linguistic Analysis of Korean Ideophones in an Extract from a Park Min-Gyu Short Story}

\author{
CRISTINA BAHÓN ARNAIZ \\ Literature Translation Institute of Korea, República de Corea
}

Resumen: Los ideófonos han recibido insuficiente atención en las lenguas románicas, entre ellas el español. No sólo han pasado inadvertidos, sino que han sido calificados como palabras periféricas, irrelevantes, anecdóticas o semánticamente insignificantes. En las últimas décadas, gracias al auge de los mangas o los webtoons, ha crecido el interés por las onomatopeyas. Sin embargo, los estudios en español relacionados con los ideófonos coreanos y las onomatopeyas son aún limitados. Este artículo, centrado en los ideófonos coreanos, pretende demostrar la relevancia de estos elementos lingüísticos en coreano, una lengua claramente ideofónica. Para ello, se explican las características lingüísticas de los ideófonos en este idioma y se realiza el análisis de un fragmento con 11 ideófonos y dos onomatopeyas

Recepción: 23 de octubre de 2020. / Aceptación: 9 de febrero de 2021. 
escrito por Park Min-Gyu, uno de los escritores más destacados de la literatura contemporánea coreana.

Palabras clave: ideófono; onomatopeya; iconicidad; coreano; mímesis.

Abstract: Ideophones and onomatopoeia have received surprisingly little attention in Romance languages, including Spanish. They have been misunderstood and marginalized as peripheral, immature, unnecessary and less-linguistic words, deprived of the significant, scholarly attention that they deserve. Recently, due to the success of mangas and webtoons, the number of studies related to onomatopoeia have increased. However, studies in Spanish related to Korean ideophones and onomatopoeia remain limited. This research, focused on Korean ideophones, aims to demonstrate the relevance of these words in Korean, a clearly phonosymbolic language. To do this, the linguistic characteristics of Korean ideophones are explained, followed by the analysis of a short text, written by the contemporary writer Park Min-Gyu, formed by eleven ideophones and two examples of onomatopoeia.

Keywords: ideophone; onomatopoeia; iconicity; Korean; mimetic words.

\section{Introducción}

Bien es sabido que unas lenguas son más ideofónicas que otras. El extenso repertorio de ideófonos presente en idiomas del este o sureste asiático, donde destacan Corea del Sur, Japón, Vietnam o Camboya y ciertos países africanos, es incomparable con el de las lenguas anglosajonas o las lenguas romances. De acuerdo con Park $(2008,12)$, el coreano contempla alrededor de 15000 ideófonos y onomatopeyas registrados en el diccionario; si se tiene en cuenta el año de publicación, es muy probable que esta cifra haya aumentado en la actualidad. Aunque un poco menos, son también relevantes las 12000 onomatopeyas e ideófonos vigentes en japonés (Inose 2009). En contraste con 
estas cifras, el inglés tan sólo cuenta con 1500 (Kim 2014, 1), lo que demuestra la brecha palpable entre unos idiomas y otros. Todavía no se ha publicado ningún estudio que verifique el número de onomatopeyas e ideófonos en español, pero los académicos afirman que las lenguas germánicas son más ricas en onomatopeyas que las románicas (García 1982, 51). Estos datos sólo aluden a las onomatopeyas, lo que permite deducir que el uso de los ideófonos será aún más reducido. El Diccionario de onomatopeyas del cómic (Gasca y Gubern 2008) es el único de este tipo en español, pero no considera los ideófonos y limita las onomatopeyas a ese género específico. Estas diferencias cuantitativas reflejan la mayor o menor trascendencia de estos vocablos en los distintos idiomas.

Tampoco se pueden ignorar las claras divergencias cualitativas. En las lenguas románicas, no sólo se confunde ideófono con onomatopeya, sino que, además, se consideran expresiones periféricas, inmaduras, innecesarias y de menor valía lingüística que otras palabras (Schourup 1993, 52). Esto también se contrapone a la envergadura de estos elementos lingüísticos en coreano o en japonés. "Los ideófonos son utilizados en todos los niveles del idioma, desde la conversación coloquial hasta los artículos de periódico de calidad, en los nombres de productos comerciales, en los cómics y, naturalmente, en las obras literarias" (Inose 2009, 32). Es decir, los ideófonos no se limitan a los cómics, la poesía o la literatura infantil, como comúnmente se piensa. Por el contrario, se utilizan en amplios ámbitos y registros, tanto formales como informales.

Probablemente por su escurridiza naturaleza, vinculada a sonidos impropios del lenguaje humano, o por el insuficiente crédito científico recibido en las lenguas románicas, la investigación relativa al campo de las onomatopeyas, y sobre todo de los ideófonos, es exigua en español. Asimismo, es incomparable el número de contribuciones académicas en coreano, japonés e inglés respecto al español. Este artículo pretende mostrar la relevancia de estos elementos lingüísticos en coreano, un idioma con una clara afluencia ideofónica. 


\section{Definición de onomatopeya y de ideófono}

El término ideófono surgió y se generalizó con la aportación del lingüista Clement Martyn Doke, estudioso de las lenguas africanas, quien además definió esta palabra como "una representación viva de una idea mediante un sonido. Una palabra, normalmente onomatopéyica, que describe la forma, color, sonido, olor, acción, estado o intensidad de un predicado, un calificativo o un adverbio" (Doke 1935, 118). También existen otras denominaciones menos utilizadas: "expresivos" (Diffloth 1972), "palabras imitativas" (Müller 1861), "onomatopeya" (Aston 1894; Urtel 1919) o "mímesis” (Akita 2009). Todas estas nomenclaturas recogen un mismo punto común relativo a la iconicidad, que entienden como la relación de semejanza entre la forma y la idea/significado que representa (Dingemanse 2015, 8). En la actualidad, las denominaciones más usadas son ideófono y onomatopeya, aunque ambas contemplan matices diferentes.

La palabra onomatopeya proviene del griego ónoma 'nombre' y poieîn 'hacer, crear'. La Real Academia de la Lengua Española la define como palabra cuya forma fónica emula el sonido de lo que representa (Diccionario de la lengua española, 21 ed. 1989, s.v. “onomatopeya”). Por otro lado, Gasca y Gubern $(2008,8)$ la clarifican como "figura retórica de dicción y, más precisamente, un icono acústico, pues aspira a convertirse en traducción, oral y/o escrita, de los ruidos”. Sonidos como guau o miau, para representar el ladrido de un perro o el maullido de un gato, son ejemplos de onomatopeya.

Los ideófonos son más difíciles de definir. De hecho, ni siquiera la RAE recoge una entrada para este término. Eso demuestra el escaso análisis científico de estos vocablos en ciertas lenguas, entre ellas el español. La definición más generalizada es, sin duda, la ofrecida por el creador del término, Clement Martyn Doke. Sin embargo, otros lingüistas los han descrito como "unidades lingüísticas, con rasgos lingüísticos multimodales marcados, que representan imágenes sensoriales" (Din- 
gemanse 2012, 1) ${ }^{1}$ o "signos del lenguaje marcados que reflejan impresiones e impulsos sensoriales" (Wojciechowski 2013, 29). ${ }^{2}$ Estas explicaciones son más aclaratorias, ya que los ideófonos no sólo representan simples ideas, sino también sensaciones o impulsos. Es decir, son palabras que evocan imágenes sensoriales, perceptibles a través de los sentidos, de una cierta idea, acción, intensidad, forma o sensación, entre otros. Se clasifican en tres tipos (Akita, 2009):

i. Fonómimos: imitan sonidos de seres vivos u objetos inanimados. Se conocen comúnmente como onomatopeyas. Sonidos como guau o miau, que representan el ladrido de un perro o el maullido de un gato, formarían parte de esta categoría. De acuerdo con esta clasificación, se podría decir que las onomatopeyas son un tipo de ideófono, más exactamente, un fonómimo. Algunos ejemplos de fonómimos en coreano son: meongmeong 멍멍 ('guau-guau') o gaegolgaegol 개골개골 ('croac-croac').

ii. Fenómimos: describen o representan estados, movimientos, condiciones o formas, es decir, expresan ideas o impresiones provenientes de otros sentidos distintos al auditivo, como la vista, el gusto, el olfato o el tacto. Son, por tanto, plenamente descriptivos. En coreano formarían parte de esta categoría fenómimos como mallang-mallang 말랑말랑, utilizado para describir algo blando y suave, o kamkambada 캄캄하다 para referirse a una oscuridad intensa, entre otros.

iii. Psicómimos: expresan o representan estados psicológicos o emocionales y sentimientos, como, por ejemplo, sseupsseulbada 씁쓸하다, dapdapada 답답하다 o $\dddot{j i p j j i p a d a ~ ㅉ ㅣ ㅂ ㅉ ㅣ ㅂ ㅎ ㅏ ~}$ 다, que manifiestan disgusto, frustración e insatisfacción respectivamente.

1 "marked words that depict sensory imagery".

2 "marked language signs that reflect impressions and sensory impulses". 


\section{Características lingüísticas de los ideófonos coreanos}

Los ideófonos coreanos presentan dos características fonosimbólicas destacables: apofonía vocálica de vocales de convergencia positiva y negativa, y apofonía consonántica o mutación consonántica.

El coreano consta de 21 vocales, de las cuales 10 son simples y 11 compuestas o diptongos.

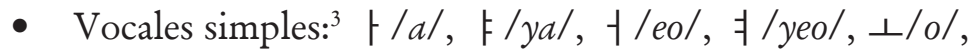
$\Perp / y_{0} /, \boldsymbol{\top} / u /, \pi / y u /,-/ \mathrm{eu} /, \mid / i /$

- Vocales compuestas y diptongos: H/ae/, H/yae/, - l/e/, 키/ye/, 니/oe/, 끼/wi/, 기/ ui/, 가/wa/, 꺼/wo/, 내/ wael, 게/wel

Estas vocales pueden ser afectadas por el fenómeno lingüístico de la armonía vocálica, que altera los fonemas de cierto tipo al restringir las combinaciones de aquellos que carecen de armonía (Arias 2005, 120). Consecuentemente, se distinguen tres tipos de vocales en coreano: frontales o claras, medias $\mathrm{u}$ oscuras y neutras (Kim 2011, 19).

- Vocales claras o frontales: $\mid / a /, \vDash / y a /, \perp / o /, \Perp /$ yo/, H/ael, H/yael, 나/wal, 내/wael, 니/oel

- Vocales oscuras o medias: $\dagger /$ eo/, $\neq$ / yeo /, Т/u/, т/ yu/, 꺼/ wo/, 케/e/, 키/ye/, 끼/wi/, ㄱ/ wi/, 께/we/

- Vocales neutras: - /eu/, |/il

La armonía vocálica se basa en la combinación de vocales claras con claras y vocales oscuras con oscuras, sin mezclar unas con otras, aunque siempre puede haber excepciones. Los ideófonos y las onomatopeyas presentan, en su mayoría, armonía vocálica. Cada una de estas vocales transmite cualidades dife-

${ }^{3}$ El método de romanización usado en este artículo es la romanización revisada del coreano. 
rentes. Las vocales claras o frontales evocan ligereza, lentitud, pequeñez, delicadeza, finura y positividad. Sin embargo, las vocales medias u oscuras sugieren pesadez, grosor, enormidad, intensidad, amplitud y negatividad (Chewan 1987, 24). Según las vocales que conformen el ideófono o la onomatopeya, el matiz que transmitirá será ligeramente diferente. Por ejemplo, los ideófonos banjjak-banjjak 반짝반짝 (formado por vocales claras) y beonjjeok-beonjjeok 번쩍 번쩍 (formado por vocales oscuras) describen algo que brilla. No obstante, el primero alude a algo de tamaño pequeño, de acuerdo con las características de las vocales frontales, mientras que el segundo sugiere algo de tamaño mayor, que brilla con intensidad. Otro ejemplo lo encontramos en 'gordo', expresado a través de los ideófonos tungtunghada 퉁퉁하다 (con vocales oscuras) y tongtonghada 통 통하다 (con vocales claras). Se han tomado estos dos términos, de entre otras variedades, para observar el matiz semántico que transmiten las vocales claras a las oscuras y viceversa. El ideófono tongtonghada 통통하다, formado por vocales claras, denota cierta positividad, del mismo modo que en español no es lo mismo decir 'gordo' que 'rechoncho' o 'regordete'. Es un término más fino y delicado, y se usa para referirse, con cierta ternura, a algo pequeño, como un bebé, un animal o una persona algo rechoncha. Por el contrario, tungtunghada 퉁퉁 하다 comporta mayor pesadez, grosor y, sobre todo, negatividad. Se puede observar que, aunque a simple vista no sean más que pequeños matices semánticos, el detalle, la imagen y la sensación que transmiten difieren levemente.

Respecto a las consonantes, el coreano está compuesto de 19 fonemas consonánticos. Se distinguen tres categorías en los fonemas plosivos y africados: $i$ ) planos (tres fonemas plosivos planos y un fonema africado plano); ii) tensos (tres fonemas plosivos tensos y un fonema africado tenso), y iii) aspirados (tres fonemas plosivos aspirados y un fonema africado aspirado), como se muestra a continuación: 


\begin{tabular}{|c|c|c|}
\hline $\begin{array}{l}\text { Fonemas plosivos planos } \\
{[\forall / b, p /],[\subset / d, t /],[\neg / g, k /]}\end{array}$ & 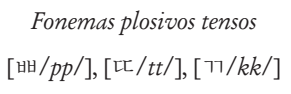 & $\begin{array}{l}\text { Fonemas plosivos aspirados } \\
{[\text { 프/p/], [E/t/], [ᄏ/k/] }}\end{array}$ \\
\hline $\begin{array}{c}\text { Fonema africado plano } \\
{[\pi / j /]}\end{array}$ & $\begin{array}{c}\text { Fonema africado tenso } \\
{[\text { [x/ } / j j /]}\end{array}$ & $\begin{array}{c}\text { Fonema africado aspirado } \\
{[\text { ㅊ/ch/] }}\end{array}$ \\
\hline
\end{tabular}

En este caso, la apofonía consonántica o mutación consonántica consiste en la variación de fonemas planos por fonemas tensos o aspirados, o viceversa, para intensificar o lenificar el significado del ideófono (Park 1996, 189). Es decir, por un lado tenemos la apofonía vocálica, la cual transmite sensaciones diferentes respecto a ligereza, lentitud, pequeñez, delicadeza, finura y positividad; y por otro, la apofonía consonántica, con la que se intensifica o lenifica la connotación semántica y expresiva de los ideófonos. Por ejemplo, tanto dandanhada 단단하다 como tantanhada 탄탄하다 describen algo firme y fuerte. Sin embargo, la apofonía consonántica del fonema plosivo plano $[\sqsubset / d, t /]$ por el fonema plosivo aspirado $[E / t /]$ produce una fortición semántica y expresiva. Estas características fonéticoprosódicas no causan cambios semánticos sustanciales, pero transmiten imágenes y sensaciones diferentes, además de comunicar el significado con mayor viveza. En otras palabras, no sólo realizan una función semántica representativa con la que transfieren un significado, sino que cumplen también una función expresiva.

Con respecto a las características morfológicas, los ideófonos coreanos pueden ser clasificados en dos grandes grupos de acuerdo con su forma: simples y reduplicados, estos últimos como los más empleados (Park 2016, 50). Los ideófonos simples están constituidos por un tema, es decir, una base morfológica a partir de la cual se pueden crear palabras autónomas, y pueden estar formados por una, dos, tres o cuatro sílabas:

- Kkok 꼭, con una sílaba, es un ideófono polisémico que se utiliza para enfatizar la realización de una acción sin falta alguna, entre otros. 
- Kkamjjak 깜짝, con dos sílabas, alude a una sensación de sorpresa o susto repentino.

- Hururuk 후루룩, con tres sílabas, describe el sonido producido al sorber una pequeña cantidad de líquido con rapidez, o el aleteo ligero de un pájaro.

- Sigeunbeoltteok 시근벌떡, con cuatro sílabas, retrata a una persona sin aliento, jadeando con dificultad.

Por el contrario, los ideófonos reduplicados están formados por dos o más temas. La forma reduplicada implica pluralidad, continuidad, prolongación, énfasis y repetición. Es decir, tiene una función importante de ampliación e intensificación semántica (Chewan 1993, 62). El ideófono kkamppak 깜빡, en forma simple, reproduce algo que se abre y se cierra o se oscurece y brilla, ya sean unos ojos o una luz parpadeante como la luz de un faro, de un semáforo o del intermitente de un coche. En forma reduplicada, kkampppak-kkamppak 깜빡 깜빡 intensifica la velocidad de ese parpadeo, según las características mencionadas. Esta duplicación puede ser de sílabas idénticas (forma AA/AAA, por ejemplo: kkok-kkok 꼭꼭/ $k k o k-k k o k-k k o k$ 꼭꼭꼭), de dos sílabas (ABAB/AABB, por ejemplo: burya-burya 부랴부랴, de forma $\mathrm{ABAB}$ o sisi-kolkol 시시콜콜, de forma $\mathrm{AABB}$ ) y de tres sílabas (ABCABC, por ejemplo: duribeon-duribeon 두리번두리번). Por otro lado, está la reduplicación de sílabas análogas, es decir, la repetición de un ideófono de dos temas que son parecidos, pero no idénticos (Chewan 1993, 105). Algunos ejemplos de este tipo de repetición serían alssong-dalssong 알쏭달쏭, con forma $\mathrm{ABA}{ }^{\prime} \mathrm{B}, \mathrm{o}$ heodung-jidung 허둥지둥, con forma $\mathrm{ABCB}$. Este estudio, más que analizar en profundidad las características morfológicas de los ideófonos coreanos, lo que pretende es dar a entender el matiz que transmite un ideófono en forma simple respecto a otro en forma reduplicada, con el fin de manifestar el detalle semántico y expresivo de estos elementos lingüísticos tan únicos y singulares del coreano. 
Otra característica relevante de los ideófonos coreanos es su cualidad de derivar en palabras de otra categoría gramatical: verbos, adjetivos, sustantivos o adverbios. Esto se produce a través de su combinación con diferentes sufijos, entre ellos estos seis como los más utilizados: -hada-하다, -georida-거리 다, -daeda -대다, -ida-이다, - $i$-이 e - $b i$-히. Por lo general, a través de los sufijos -hada -하다, -georida -거리다, -daeda -대 다 e -ida-이다, el ideófono, que funciona originalmente como adverbio, deriva en verbo, aunque -hada -하다 también permite que se transforme en adjetivo; por ejemplo: ppudeutada 뿌듯하다 'satisfecho'; teunteunbada 튼튼하다 'fuerte, firme'; ttakttakada 딱딱하다 'sólido, rígido'; singsinghada 싱싱하다 'fresco'; ssaneulhada 싸늘하다 'frío' o ppyojokada 뾰족하다 'afilado', entre muchos más. Con el sufijo - $i$-이, el ideófono funciona como sustantivo, aunque tanto $-i-$ 이 como - $h i-$ 히 también permiten que algunos ideófonos sin autonomía propia funcionen como adverbios (I. Kim 1995, 4; H. Kim 1995, 126; Lee 1993,12).

Con este sucinto resumen de las características fonosimbólicas y morfosintácticas de los ideófonos coreanos se pretende enfatizar el detalle semántico y la función expresiva de estas palabras, capaces de evocar imágenes sensoriales, perceptibles a través de los sentidos. Los ideófonos destacan además por su carácter perlocutorio, es decir, transmiten emociones que producen un efecto en el receptor, mayor que con cualquier otra palabra (Wojciechowski 2013, 30). Dicho esto, se puede añadir que "los ideófonos son unidades lingüísticas, formalmente notorios por sus rasgos lingüísticos multimodales marcados y con una función expresiva vívida y claramente dramatúrgica" (Dingemanse 2012, 2019; Ibarretxe-Antuñano 2017; Akita y Pardeshi 2019; Akita y Dingemanse 2019).

En lo que atañe a la función expresiva de los ideófonos, y más en relación con el campo de la literatura, estos elementos contemplan aspectos dramáticos, es decir, no sólo describen una realidad con enorme detalle (suelen tener además naturaleza polisémica), sino que la representan con eficacia, viveza 
y de manera dinámica, como si de "gestos verbales" se tratase (Nuckolls 2001, 2006). Este detalle semántico, expresivo, dramatúrgico e incluso estilístico "cuando marcan posiciones o elementos de foco en una estructura sintáctica" (Ibarretxe 2006, 13), hace que sean elementos lingǘsticos especiales. Por ejemplo, cuando una persona se siente disconforme por algo que no termina de satisfacerla, en español se puede decir simplemente 'estar insatisfecho' o exteriorizarlo de un modo más expresivo con 'haberse quedado con un mal sabor de boca', mientras que en una lengua ideofónica como el coreano ese estado se podría expresar con 'jjipjjipada 찝찝하다'. Los ideófonos son palabras muy expresivas, con alta capacidad alegórica al suscitar imágenes y transmitir sensaciones en el receptor. La vivacidad, el ritmo, la musicalidad y la alegoría de estas palabras permiten su uso en diferentes ámbitos y géneros, como el literario (CasasTost 2008, 13-14). A continuación, se analizará un fragmento de un relato corto de Park Min-Gyu.

\section{Análisis de los ideófonos en un texto literario de Park Min-Gyu}

Una vez presentadas las características generales de los ideófonos coreanos, se examinarán en un texto literario para entender su papel semántico y expresivo aplicado al campo de la literatura. Como ya se mencionó, los ideófonos coreanos se usan habitualmente en diversos campos: "conversaciones, escritos, literatura, titulares, artículos de periódico o noticias, entre otros, para aportar más detalle, viveza y expresividad" (Bahón $2019,46)$. Por razones de espacio, en este artículo sólo se analizará un fragmento de un cuento, aunque no se descarta un análisis futuro de los ideófonos en diferentes géneros: cómics, webtoons, poesía, artículos de periódico, noticias de televisión, redes sociales, conversaciones, etcétera.

El texto seleccionado es un fragmento del relato corto "Gabeul gosiwon cheryugi" 갑을고시원 체류기 [La historia 
de mi estancia en el gosiwon Gabeul], del libro Kaseutera 카 스테라 [Bizcocho], escrito por Park Min-Gyu (1968-), uno de los escritores más distintivos de la literatura contemporánea coreana. Es un autor con un estilo único y original, escribe prosa en forma de verso, añade colores a sus palabras e incluso varía el tamaño de las grafías en sus obras. Debutó en 2003 con dos novelas, ganadoras del premio Munhak Dongne: Jigu yeongungjeonseol 지구 영웅전설 [Leyenda de los superhéroes del mundo] y Sammi syupeoseutajeuni majimak paenkeulleop 삼 미 슈퍼스타즈의 마지막 팬클럽 [El último club de fans de los Sammi Superstars]. Esta última fue traducida al español. Además, consiguió el premio Yi Sang dos veces con dos relatos cortos: "Gomawo, gwayeon neoguriya" 고마워, 과연 너구리 야 [Gracias, Mapache] y "Achimui nun" 아침의 눈 [La puerta de la mañana] en 2005 y 2010 respectivamente. Su novela Jugeun wangnyeoreul wihan pabanneu 죽은 왕녀를 위한 파반 느 [Pavana para una princesa muerta] fue traducida al inglés, al francés y al italiano, entre otros, y es una de sus obras más traducidas internacionalmente.

La razón por la que elegí este texto de la gran variedad de novelas y cuentos de la literatura coreana es porque tuve la oportunidad de traducirlo en el Literature Translation Institute of Korea (LTI Korea), bajo la dirección de un profesor especializado y del propio Park Min-Gyu, con quien pudimos analizar en detalle el significado de la obra.

"Gabeul gosiwon cheryugi" narra las vivencias de un muchacho veinteañero en el gosiwon Gabeul. Un gosiwon es la modalidad de residencia más barata en Corea del Sur, de muy reducidas dimensiones (cada habitación suele medir unos $2 \times 3 \mathrm{~m}^{2}$ ), que en la mayoría de los casos carece incluso de ventanas (el gosiwon Gabeul no las tiene). En este limitado espacio se colocan una mesa, una silla, una cama, un televisor $\mathrm{y}$ un pequeño frigorífico.

La historia se remonta a 1991, momento en el que el protagonista pasa una temporada en este gosizwon debido a la bancarrota familiar y al embargo de la casa donde vivía con sus 
padres y su hermano. No sólo es curioso cómo el relato gira en torno a un gosiwon, también llama la atención el nombre: gosiwon Gabeul —en la novela aparece como nombre propiohace referencia al término coreano Gab-Eul 갑을, que denota las dos partes que formalizan un contrato, Gabla parte con poder y Eul la otra, en posición de desventaja. Este es un tema con gran repercusión social del que se han escrito muchos artículos: "Decir que alguien es el Gab en una situación específica significa que esa persona disfruta de una posición ventajosa respecto a otra, a la que se denomina Eul" (Kwon 2014, 19)..$^{4}$ El nombre del gosiwon conlleva una crítica al cuestionable uso del poder de una parte de la sociedad sobre otras.

El protagonista de la historia se encuentra en este lugar, donde vive un par de años hasta salir de la crisis económica en la que está sumergido, con el fiscal Kim, el último estudiante para un puesto de alto cargo público en el gosiwon. Ambos viven en cuartos contiguos y comparten experiencias no del todo agradables que recordarán durante el resto de sus vidas.

Antiguamente, los gosiwones eran usados por estudiantes que se preparaban para ser funcionarios. La palabra gosi 고시, de etimología china (高試), hace referencia a una prueba de alto nivel, como el examen estatal mediante el cual se selecciona a los empleados públicos (Hangugeogichosajeon 한국어기초사전 [Diccionario básico de coreano], s.v. “gosi 고시”). Esto es algo relevante en la historia, ya que el fiscal Kim es el último que se prepara para un examen público en este gosiwon. A partir de los años noventa, los gosiwones comenzaron a ser usados por todo tipo de estudiantes, como el mismo protagonista, así como por trabajadores de bajos ingresos, esporádicos, e incluso por empleados de locales nocturnos. Es interesante ver cómo en un gosiwon con un nombre tan llamativo, el fiscal Kim es objeto de un trato claramente preferente de la dueña, quien hace guardar un estricto silencio a todos los residentes para no interrumpir

4 "to say that someone is Gab in a situation means that s/he enjoys an advantageous position vis-à-vis the other party, whom we would consequently call the Eul in the situation". 
su larga jornada de estudio, entre otros detalles. Por otro lado, también destaca cómo el fiscal Kim — quien ni siquiera es fiscal todavía, pero al que llaman así porque asumen que algún día lo será- pasea por el gosiwon con plena confianza, orgulloso, mientras el resto de los huéspedes intentan no coincidir unos con otros porque se avergüenzan de sí mismos. A pesar de ser un relato corto donde se narran las vivencias de un joven con problemas económicos, es interesante la manera tan sugerente en que muestra aspectos de la sociedad coreana con un toque de humor, predominante en las obras de Park Min-Gyu.

El objetivo de este análisis ideofónico es observar, de modo práctico, las características lingüísticas descritas con anterioridad. Se atenderá especialmente la función semántica y expresiva de los ideófonos, así como su capacidad de transmitir sentimientos e impulsos sensoriales con una carga emotiva y perlocutiva (Wojciechowski 2013,29) “a través de la percepción o sensación del conocimiento adquirido a partir de la experiencia sensorial" (Ibarretxe 2020, 416). Con esto no se pretende afirmar que los ideófonos son los únicos elementos que desempeñan funciones semánticas o expresivas; sin embargo, es importante valorar cómo complementan semántica y expresivamente el texto, y entender su relevancia lingüística en idiomas como el coreano, cuando en español pasan completamente inadvertidos.

Aquí sólo se analizará un fragmento con contundente presencia ideofónica de 11 ideófonos y dos onomatopeyas. Este texto que traduje se inclina a la literalidad para hacer un análisis lingüístico más riguroso. El protagonista hace una descripción del fiscal Kim, su vecino en el gosiwon, y narra cómo coincidieron un día en el bar donde el protagonista trabajaba por horas. Al tratarse de un futuro fiscal, aprovechó la oportunidad para confesarle cómo se había arruinado su familia e intentó solucionar sus dudas legales. Es, por tanto, un texto descriptivo-narrativo en el que se ha respetado el peculiar estilo del autor, con frases entrecortadas o separadas. 
El único hombre que no se sentía avergonzado de sí mismo en este lugar era el fiscal Kim. Él siempre se mostraba seguro de sí, mantenía su postura recta (1) ante cualquiera y se esforzaba en todo lo que hacía. Subía a la azotea y hacía gimnasia a las seis de la mañana y a las nueve de la noche, y cuando era su hora de comer, colocaba sus acompañantes en la mesa con confianza, sin importarle quién estuviese ahí. No sé cómo describirlo, pero era una excesiva vanidad que llegaba a provocar vergüenza ajena.

Por ejemplo, cuando hacía gimnasia, echaba la espalda hacia atrás sacando la pelvis - aunque hubiese mujeres ahí-y, estirando por completo (2) una pierna, movía su trasero de arriba abajo (3) con todas sus fuerzas. Creo que, si hubiera sido yo, no habría podido hacer ni ejercicios de respiración. Además, cuando se lavaba la cara - por supuesto sin importarle quien estuviese ahí- paf, paf (4), se frotaba con fuerza (5) el rostro y el cuello hasta llegar a enrojecerlos. Después, moc (6), se sonaba la nariz y finalizaba su rutina agitando con ímpetu (7) la mano para desprenderse de esa masa de mocos. Si hubiera sido yo...

Mejor me callo.

El fiscal Kim era así. Estaba orgulloso de haberse graduado de la carrera de derecho y era notorio el trato especial que recibía de la dueña. Por supuesto, él era claramente el mayor, por lo que siempre que necesitaba algo se dirigía a la mayoría de la gente dando órdenes de un modo autoritario. Cuando el fiscal Kim subía a la azotea, todos los hombres y las mujeres que hablaban y reían se callaban de inmediato. $\mathrm{Al}$ menos en este lugar, él era todo un fiscal.

Cada vez que me encontraba con él, lo saludaba sin falta (8). Por lo general, me topaba con él en la azotea o en la mesa de comer, pero hubo justo (9) una vez en que coincidimos en el bar donde yo trabajaba por horas. Me sorprendí de verlo ahí, y al saludarlo, se sonrojó. No estoy seguro, pero su expresión era como si lo hubiera descubierto haciendo algo indebido. ¡Una cerveza de $500 \mathrm{ml}$ ! Al ver que bebía solo, sin siquiera un plato de acompañamiento, le pedí el favor al cocinero y le ofrecí un calamar seco. En ese momento no había más clientes ni tampoco estaba el dueño.

$-¿$ Qué es esto?

-Invita la casa.

Asintió (10) con rostro indiferente. Aprovechándome de esta oportunidad, me senté frente a él y, desmenuzando un tentáculo del calamar, comencé a hablarle de distintos temas. Por supuesto, tenía una razón para hacer esto. En primer lugar, le expliqué en detalle cómo se había arruinado mi familia, y después le pregunté si era cierto que, aunque mi hermano o yo trabajásemos, nos embargarían todo (11) el sueldo. 
¿Tenemos que pagar "legalmente" las deudas de nuestro padre? ¿Nos imponen esa "obligación legal"? ¿Por qué no nos dejan vivir? ¿Debemos pagar "legalmente" esta deuda hasta que nos muramos? De este modo, le pregunté en detalle acerca de todo lo que me hacía sentir frustrado (12). Con gesto molesto, su respuesta tras escuchar mis quejas en silencio fue corta y simple.

-Si pides un préstamo, tienes que pagarlo.

Al desaparecer la nuca de ese cerdo inútil que subía hacia la colina, sopló una brisa cálida (13). Justo estaba fumando al lado de la salida del aire acondicionado. El mundo seguía tranquilo y los cerezos a la entrada ya ni siquiera se mecían. Él era sin duda el fiscal Kim, el mismo que había tocado la puerta de mi habitación en mi primera noche. Así es.

Se transcribe a continuación el original coreano para realizar el análisis con todos los ideófonos numerados.

"이곳에서 자신을 부끄러워하지 않는 남자는 오직 김검사뿐이었다. 그는 언제나 당당했고, 누구 앞에서나 꼿꼿했으며 (1), 무엇을 해도 늘 열심이었다. 새벽 여섯시와 밤 아홉시엔 어김없이 옥상에 올라 와 맨손체조를 했고, 밥을 먹을 시간이 되면 식탁에 누가 있더라도 당당히 자신의 반찬을 늘어놓았다. 그것은 뭐랄까, 보는 사람이 민 망할 정도의 당당함이었다.

예컨대 체조를 해도 -여자들이 있는데도- 허리를 한껏 젖히며 골반을 내민다거나, 한쪽 다리를 짝 (2) 벌려 엉덩이를 들썩이는 (3) 동작을 그렇게 열심히 하는 것이다. 아마 나라면, 숨쉬기 운동도 제 대로 못 할 것이다. 또 세수를 해도 -물론 누가 있더라도- 푸파푸파 (4) 엄청난 소리를 내며 얼굴과 목이 뻘겅게 될 정도로 빡빡 (5) 문 지를 후, 킁 (6) 하고 크게 코를 풀어 그 덩어리를 탁 (7) 떨치는 것 으로 늘 마무리를 하고는 했다. 아마 나라면.

말을 말자.

김검사는 그런 인물이었다. 그리고 그 배후에는 법대 출신이라 는 자존심과 주인아줌마의 각별한 대우가 늘 자리잡고 있었다. 물 론 나이로도 가장 연장자임이 분명했지만, 그는 자신이 필요할 때 늘 대부분의 사람들에게 명령조의 반말을 썼다. 남자들은 물론, 즐 겁게 웃고 떠들던 여자들도 김검사가 옥상에 올라오면 일제히 입을 다물었다. 적어도 이곳에선.

그는 완전한 검사였다.

그와 마주칠 때마다 나는 꼬박꼬박 (8) 인사를 했다. 대개가 옥 상이나 식탁에서였는데, 딱 (9) 한 번 아르바이트를 하던 호프에서 그를 만난 적이 있었다. 인사를 하던 나도 놀랐고, 인사를 받던 그 
도 상당히 얼굴을 붉혔다. 잘은 몰라도, 뭔가 흐트러진 모습을 남에 게 들켰다는 표정이었다. 오백 한 잔! 안주도 없이 혼자 처량히 술 을 마시길래, 나는 주방장형에게 부탁을 해 오징어를 내다주었다. 마침 손님도 주인도 없던 터였다. 뭐냐?

서비스예요.

대수롭잖다는 표정으로 그는 고개를 까딱했다 (10) 이를 핑계 로 맞은편 자리에 앉은 나는 오징어의 다리를 뜯으며 이런저런 애 기들을 늘어놓기 시작했다. 물론 이유가 있어서였다. 우선 집안의 몰락에 대해 자세히 설명을 한 후, 그래서 형이나 내가 취직을 월급 을 몽땅 (11) 차압 당한다고 들었다. <과연 법적으로> 아버지의 빚을 우리가 갚아야만 하는 것인가. <과연 법적으로> 그런 의무 가 있는 것인가. 그래도 생활은 할 수 있어야 할 것 아닌가. <과연 법적으로 > 죽을 때까지 빚을 갚아야 하는가 - 등의 평소 억울하고 답답했던 (12) 의문점들을 낱낱이 고해바쳤다. 뚱하니 나의 하소연 을 듣고 있던 그의 대답은 너무나 짧고, 간단했다.

돈을 빌렸으면 갚아야지.

언덕을 향해 올라가던 똥돼지의 뒤통수가 사라지자, 어디선가 후끈한 (13) 바람이 불어왔다. 하필이면 에어컨의 통풍구 곁에서 나 는 담배를 물고 서 있었다. 세상은 여전히 정숙했고, 저 멀리 진입로 쪽의 벚꽃나무들은 미동도 하지 않은 채 서 있었다. 그러니까 - 그 가 바로 첫날 밤 내 방문을 두드렸던 김검사였다. 정말이지” (Park 2012, 289-290).

Lo primero que llama la atención es la gran cantidad de ideófonos e incluso onomatopeyas incluidos en este corto fragmento, algo que sería muy difícil, por no decir imposible, de encontrar en idiomas como el español.

El ideófono (1) kkot-kkot 꼿꼿- es polisémico, al igual que la mayoría de estos elementos lingüísticos. Por un lado, describe la postura recta de una persona resaltando su verticalidad o la posición vertical de un objeto. Y, por otro, desde una perspectiva menos física y más psicológica, aunque ambas pueden estar correlacionadas, alude a alguien de corazón o personalidad recta, firme y honesta. En el texto, kkot-kkotada 꼿꼿하다 representa la postura recta del fiscal Kim y complementa, de modo gráfico, la imagen visual de su confianza y su autoestima, en torno a las cuales gira el primer párrafo. Por supuesto, no se pretende generalizar, pero caminar recto, sacando el pecho, 
es un rasgo de alguien con autoestima alta, y kkot-kkot 꼿꼿ayuda a simbolizar esto gráficamente.

El ideófono kkot-kkot ᄁᄁㅅㅅ꼿 está formado por la vocal frontal o clara $\perp / \%$. De acuerdo con las características fonosimbólicas de los ideófonos coreanos, también se encuentra la forma kkut-kkut 꿋꿋-, con la vocal media u oscura T/u/. El ideófono kkut-kkut 꿋꿋-, al igual que kkot-kkot 꼿꼿-, siempre aparece acompañado de las distintas combinaciones del sufijo hada -하다, que expresa fuerza y firmeza, al punto de no poder doblarse o romperse. Asimismo, desde una perspectiva psicológica, alude a la voluntad o la actitud firme de una persona que no se doblega ante ninguna dificultad. De este modo, la apofonía vocálica transmite matices semánticos y expresivos diferentes.

En el segundo párrafo continúa la descripción del fiscal. Destaca por el alto grado de fonosimbolismo adyacente. Aparecen cuatro ideófonos, dos onomatopeyas y la palabra fonosimbólica ppeolgeoke 뻘겋게. En el texto, ppeolgeota 뻘겋 다 hace referencia a cómo se enrojecía su piel al frotarse con tanta fuerza. Esta vocal media u oscura refleja un rojo intenso y oscuro, distinto al de ppalgata 빨갛다, que evoca un rojo claro y vivo. Como se mencionó, las vocales medias u oscuras sugieren pesadez, grosor, enormidad, intensidad, amplitud y negatividad (Chewan 1987, 24).

El primer ideófono que aparece en este corto segundo párrafo, con suculenta presencia ideofónica, es (2) jjwak 짝, que describe cómo el fiscal Kim estiraba la pierna al máximo para hacer ejercicio. Formado por un fonema africado tenso, enfatiza vívidamente cómo abría la pierna por completo. Transmite, además, una imagen icónica en el lector, la cual añade expresividad a la situación comunicativa (Voeltz y Kilian-Hatz 2001, 3). De nuevo, jjwak 짝 es un ideófono muy polisémico: manifiesta algo que se divulga, propaga o expande ampliamente (como puede ser un rumor); algo que cae de repente y en gran cantidad (como el sudor tras haber hecho ejercicio); una acción que se lleva a cabo de una vez o de golpe (como leer un libro 
de una sentada); o cuando se abre o estira algo por completo. No importa a lo que aluda, jjwak 짝 resalta la magnitud de la acción: de golpe, a cántaros, de repente, por completo, etcétera.

El ideófono (3) deulsseogida 들썩이다, ubicado justo después de jjwak 쪽, amplía la vívida descripción de cómo movía el fiscal su trasero de arriba abajo. El ideófono deulsseogida 들썩이다 traza el movimiento ascendente y descendente, en este caso de una parte del cuerpo, aunque también se usa para expresar bullicio y emoción, entre otras impresiones. Se observa, por tanto, el papel descriptivo de estos fenómimos, los cuales ofrecen una imagen visual con carga perlocutiva, ya que el ideófono "pone de relieve las características principales de la acción o proceso que representa a la vez que invita al oyente a que se proyecte en esa experiencia" (Ibarretxe 2020, 417). El párrafo desvela una imagen negativa de la figura del fiscal Kim, con claras alusiones a la vergüenza ajena que sentía el narrador al verlo realizar ciertas acciones. El carácter sensorial de los ideófonos, al ser capaces de evocar imágenes perceptibles a través de los sentidos, sirve para involucrar al lector y como complemento interlocutivo (Nuckolls 1999, 79).

A continuación, el protagonista describe cómo el fiscal Kim llevaba a cabo su rutina diaria en el cuarto de baño, que era de uso común en el gosizon, lo que significa que los inquilinos podían verse unos a otros si coincidían. De nuevo, los ideófonos y las onomatopeyas dotan al texto de un matiz semántico-descriptivo y expresivo.

En la pintura de esta rutina, en la que se lavaba la cara y se frotaba con fuerza el rostro y el cuello, se han utilizado dos ideófonos y dos onomatopeyas. En primer lugar, (5) ppak$p p a k$ 빡빡, formado por el fonema oclusivo tenso 빠 /pp/, implica que se ha producido una intensificación semántica. Así como los ideófonos mencionados, ppak-ppak 빡빡 es polisé. mico: señala el sonido producido al frotar o restregar algo con fuerza; o el generado al arrancar una hoja de papel; el modo en que alguien se corta el pelo o la barba muy corto, prácticamente 
a rape; o cuando alguien se obstina por algo con terquedad. En este caso, ppak-ppak 빡빡, combinado con ppeolgeoke 뻘겋게, expresa cómo se le enrojecía el cuello y la cara al fiscal Kim al frotarse con tanta fuerza, y complementa el verbo munjiruda 문지르다 'frotar'. La onomatopeya (7) pupa-pupa 푸파푸파, o "paf, paf”, facilita la percepción del sonido y la intensidad de los golpes a través de todos los sentidos, en especial el auditivo. Sucede lo mismo a continuación con la onomatopeya (9) keung 킁 o “moc” y el ideófono (10) tak 탁, que actúan unidos para expresar el modo tan desagradable con el que el fiscal Kim finalizaba su rutina de baño sonándose la nariz y agitando la mano con todas sus fuerzas, tal como lo indica tak 탁, para desprenderse de la masa de mocos. Es evidente cómo todos los ideófonos y las onomatopeyas de este párrafo trabajan intertextualmente con la narrativa para potenciar semántica y expresivamente la interpretación del texto. Como precisa Kilian-Hatz $(2001,157)$, el ideófono evoca en el receptor la imagen sensorial de lo que se está relatando, "no sólo de forma racional sino también con los sentidos". Se considera interesante la función estilística de las onomatopeyas, la cual permite que el lector "reproduzca" un sonido mientras lee.

El primer ideófono en la siguiente transición descriptivonarrativa es (8) kkobak-kkobak 꼬박꼬박, que indica la realización de una tarea con regularidad, sin fallar siquiera una sola vez. En el texto, el protagonista saludaba siempre al fiscal Kim cada vez que coincidían. Aunque esta primera acepción es la idónea para interpretar este apartado, kkobak 꼬박, en forma simple, también puede significar quedarse dormido de repente, sin darse cuenta. Está formado por dos vocales claras o frontales: $\perp / o / y \quad \vdash / a /$, y presenta apofonía vocálica, ya que existe el ideófono kkubeok-kkubeok 꾸벅꾸벅, compuesto de dos vocales medias u oscuras: $T / u /$ y $\dashv / e o /$. Este último tiene una connotación diferente. Por un lado, manifiesta el movimiento de dar cabezadas al dormir, pero también la forma en que una persona obedece las órdenes de otro sin rebelarse. Esta acepción contrastaría ligeramente con el significado de 
$k k o b a k-k k o b a k$ 꼬박꼬박 presente en el texto. De este modo, el intercambio de vocales claras por oscuras da lugar a matices diferentes. Respecto a sus características morfológicas, aparece en forma duplicada. Esto intensifica sutilmente su significado y, en combinación con el verbo insareul hada 인 사를 하다 'saludar', destaca cómo el protagonista siempre saludaba al fiscal Kim, sin falta, cuando coincidían en algún lugar.

A continuación, (9) ttak 딱 enfatiza cómo coincidió una sola y única vez con el fiscal Kim en el bar donde el protagonista trabajaba por horas. Al igual que el resto de los ideófonos analizados, ttak 딱 es también polisémico y sirve para complementar un verbo, un adjetivo o un sustantivo al indicar una cantidad justa o precisa, algo firme o fuerte y que resiste a una fuerza sin moverse, o una acción repentina. A pesar de la forma duplicada, ttak-ttak 딱딱, en este fragmento se ha utilizado de modo simple para subrayar la singularidad. Es decir, el narrador se encontró con el fiscal Kim sólo una vez, no más. La forma duplicada implicaría un significado de pluralidad, continuidad, prolongación, énfasis o repetición (Chewan 1993, 62). Este ideófono descriptivo abre el paso a la narración de cómo el protagonista aprovecha para hablarle al fiscal Kim, especializado en derecho, del embargo de la casa de su padre y de la deuda con que cargaban su hermano mayor y él a causa de eso.

El siguiente párrafo comienza con el fenómimo (10) kkattak 까딱, que describe un movimiento ligero con la cabeza o del dedo de arriba abajo, producido una sola vez, o el modo en que algo se mueve o comporta inapropiadamente. Este ideófono muestra apofonía vocálica: kkeutteok 끄떡, compuesto por vocales oscuras. Ambos presentan apenas diferencia semánti$\mathrm{ca}$, aunque kkattak 까딱 tiene un matiz más ligero, según las características de ligereza, pequeñez y finura que transmiten las vocales claras. A su vez, existe la forma duplicada kkattak$k k a t t a k$ 까딱까딱, con la que se produciría una intensificación semántica e implicaría pluralidad, es decir, no se trata de un 
solo movimiento de arriba abajo. Acompañado por daesuropjantaneun pyojeongeuro 대수롭잖다는 표정으로 'un rostro indiferente', refleja cómo el fiscal Kim asintió con indiferencia ante los problemas del protagonista. De este modo, "los ideófonos se entremezclan con otro tipo de elementos lingüísticos no ideofónicos para unir el relato intertextualmente con toda la narrativa" (Noss 2001, 269).

El ideófono (11) mongttang 몽땅, que significa 'todo, en total, por completo', exterioriza la preocupación del protagonista porque le embarguen no sólo una parte del suelo, sino todo, íntegro. En coreano existe el adverbio jeonbu 전부, que, sin ser una palabra ideofónica, también expresa totalidad. En este caso, mongttang 몽땅 aporta más expresividad, sin olvidar que el ideófono evoca en el oyente la ilusión de que participa directamente en lo que se está contando, al invitarlo a que se proyecte en esa experiencia (Kilian-Hatz 2001, 157).

Este párrafo finaliza con el ideófono (12) dapdapada 답 답하다, el cual refleja algo sofocante o asfixiante. Esto puede darse en un contexto físico, donde realmente el ambiente sea agobiante; o en un contexto más psicológico, en el que se sienta frustración, angustia o desesperación debido a una preocupación o un problema. En el texto, se describe de manera sensorial el agobio, el tormento y la desazón del protagonista por la bancarrota familiar en la que tanto él como su hermano están injustamente involucrados. Dapdapada 답답하다 aporta expresividad y viveza a esa sensación de angustia y decepción, al implicar interlocutivamente al lector.

Por último, (13) bukkeunhada 후끈하다 es un fenómimo que describe algo caliente o templado, y está formado por la vocal oscura o media $T / u /$ y la vocal neutra - /eu/. También existe el ideófono bwakkeunhada 화끈하다, compuesto por el diptongo frontal 사/wa/ y la vocal neutra -/eu/. Este ideófono indica algo caliente, por la acción del calor, y también se refiere a un modo de actuación impetuoso y decidido, desde una perspectiva más psicológico-emocional. Este matiz lo diferencia de bukkeunbada 후끈하다, que sólo hace referencia a un calor 
físico. Una duplicación del ideófono, bukkeun-hukkeun 후끈후 끈, habría enfatizado semántica y expresivamente la intensidad y la continuidad de este calor.

\section{A modo de conclusión}

Los ideófonos son elementos lingüísticos que han recibido escasa atención en español, o que se han aplicado sólo a campos específicos: narrativa infantil o cómics. En este artículo se ha intentado demostrar y defender el relevante papel semántico y expresivo de estas palabras en coreano, con el análisis de un texto literario narrativo. No sólo se han explicado las principales características fonosimbólicas y morfológicas de los ideófonos, sino que también se ha analizado su papel semántico, expresivo y perlocutivo (de involucramiento interlocutivo) en el fragmento del relato corto de Park Min-Gyu. Por razones de espacio no se han revisado más obras, pero la selección ha esclarecido, desde un punto de vista cuantitativo, el común y extenso uso de los ideófonos en la literatura coreana, en particular de 11 ideófonos y dos onomatopeyas. Y, más importante, desde un punto de vista cualitativo, se ha observado el detalle semántico y expresivo que el ideófono aporta, pues "representa de forma sensorial el evento que se está comunicando" (Ibarretxe 2020, 421).

Las particularidades mencionadas de los ideófonos pueden parecer dudosas, e incluso exageradas, desde una posición de desinterés e ignorancia de estos elementos y de desconocimiento de su uso en las lenguas ideofónicas. No es la intención afirmar que los ideófonos son los únicos medios para desempeñar funciones semánticas o expresivas; al contrario, se invita a entender sus funciones comunicativas, el detalle, el involucramiento sensorial con el interlocutor, la viveza y, si se puede, la estética que aportan al texto. Sin ánimo de limitar los ideófonos al ámbito de la literatura, se pretende en futuros trabajos analizar su papel en periódicos, noticias y demás registros del idioma 
para manifestar su relevante desempeño en lenguas ideofónicas como el coreano.

\section{Referencias}

AkITA, Kimi. 2009. “A Grammar of Sound-Symbolic Words in Japanese: Theoretical Approaches to Iconic and Lexical Properties of Japanese Mimetics". Tesis de doctorado. Kobe University. http://www.lib.kobe-u.ac.jp/repository/thesis/d1/D1004724. pdf

AkITA, Kimi y Mark Dingemanse. 2019. "Ideophones (Mimetics, Expressives)". En Oxford Research Encyclopedia of Linguistics, editado por M. Aronoff. Oxford: Oxford University Press. https://doi.org/10.1093/acrefore/9780199384655.013.477

AkITA, Kimi y Prashant Pardeshi, eds. 2019. Ideophones, Mimetics and Expressives. Amsterdam: John Benjamins. https://doi. org/10.1075/ill.16

ArIAS-CACHERo CABAL, Álvaro. 2005. "La armonización vocálica en fonología funcional (de lo sintagmático en fonología a propósito de dos casos de metafonía hispánica”. Moenia: Revista Lucense de Lingüistica y Literatura, núm. 11: 111-139. http://hdl.handle. net $/ 10347 / 5730$

Aston, W. G. 1894. "Japanese Onomatopes and the Origin of Language". The Journal of the Anthropological Institute of Great Britain and Ireland 23: 332-362. https://doi.org/10.2307/2842085

BAHÓN ARnaIZ, Cristina. 2019. "Ideófonos en coreano: aspectos lingüísticos y literarios”. Tesis de doctorado. Universidad Autónoma de Madrid. http://hdl.handle.net/10486/690282

CASAs-Tost, Helena. 2008. "Estudio comparativo de las onomatopeyas chinas y españolas". En Nuevas perspectivas de investigación sobre Asia Pacífico, coordinado por Pedro San Ginés Aguilar, 339-353. Granada: Universidad de Granada.

CHEWAN. 1987. "Gugeo eumseong sangjingnonui myeon munje" 국어 음성상징론의 몇 문제 [Algunos problemas del fonosimbolismo coreano]. Gugeobak 국어학16. https://kiss.kstudy.com/thesis/ thesis-view.asp?key $=184721$

CHEWAN. 1993. "Uiseongeo-uitaeeoui tongsawa uimi" 의성어-의태 어의 통사와 의미 [Características sintácticas y semánticas de 
los ideófonos coreanos]. Saegugeosaenghwal 새국어생활 3 (2): 54-72. https://www.korean.go.kr/nkview/nklife/1993_2/3_3. html

Diffloth, Gérard. 1972. “Notes on Expressive Meaning”. En Papers from the Eighth Regional Meeting, Chicago Linguistics Society, editado por Paul M. Peranteau, Judith N. Levi y Gloria C. Phares, 440-447. Chicago: Chicago Linguistics Society.

Dingemanse, Mark. 2012. "Advances in the Cross-Linguistic Study of Ideophones”. Language and Linguistics Compass 6 (10): 654-672. https://doi.org/10.1002/lnc3.361

DingemAnSe, Mark. 2015. "Arbitrariness, Iconicity, and Systematicity in Language”. Trends in Cognitive Sciences 19 (10): 603-615. https://doi.org/10.1016/j.tics.2015.07.013

Dingemanse, Mark. 2019. "Ideophone' as a Comparative Concept". En Ideophones, Mimetics, and Expressives, editado por Kimi Akita y Prashant Pardeshi, 13-33. Amsterdam: John Benjamins. https://doi.org/10.1075/ill.16.02din

Doke, Clement M. 1935. Bantu Linguistic Terminology. Londres: Longmans, Green, and Co.

García Yebra, Valentín. 1982. Teoría y práctica de la traducción. Madrid: Gredos.

GasCA, Luis y Román Gubern. 2008. Diccionario de onomatopeyas del cómic. Madrid: Cátedra.

IBARRETXE-ANTUÑANO, Iraide. 2006. "Estudio lexicológico de las onomatopeyas vascas: el Euskal Onomatopeien Hiztegia: EuskaraIngelesera-Gaztelania". Fontes Linguae Vasconum 101 (38): 147162. https://binadi.navarra.es/registro/00007105

IBARRETXE-ANTUÑANO, Iraide. 2017. "Basque Ideophones from a Typological Perspective". Canadian Journal of Linguistics/ Revue canadienne de linguistique 62 (2): 196-220. https://doi. org/10.1017/cnj.2017.8

IbARRETXE-ANTUÑANO, Iraide. 2020. "Ideófonos y poesía”. Tropelías. Revista de Teoría de la Literatura y Literatura Comparada, núm. 7: 411-425. https://papiro.unizar.es/ojs/index.php/tropelias/ article/view/4792

INOSE, Hiroko. 2009. "La traducción de onomatopeyas y mímesis japonesas". Sendebar: Revista de la Facultad de Traducción e Interpretación, núm. 20: 31-47. http://revistaseug.ugr.es/index. $\mathrm{php} / \mathrm{sendebar/article/view/390}$ 
Kilian-Hatz, Christa. 2001. "Universality and Diversity: Ideophones from Baka and Kxoe". En Ideophones, editado por F. K. Erhard Voeltz y Christa Kilian-Hatz, 155-163. Amsterdam: John Benjamins. https://doi.org/10.1075/tsl.44.13kil

Kim, Do-Hun. 2014. "Han-yeong uiseongeo-uitaeeo bigyo mit beonyeong gibeop" 한-영 의성여의태어 비교 및 번역 기법 [Comparación entre la onomatopeya coreana-inglesa y la traducción de la onomatopeya coreana al inglés]. Hangukbeonyeokhakoe 한국번역학회 15 (1): 25-50. https://doi.org/10.15749/ jts.2014.15.1.002 https://www.kci.go.kr/kciportal/landing/ article.kci?arti id =ART001862798

KIM, Hong-Beom. 1995. "Hangugeo sangjingeoui tongsa-uimironjeong yeongu" 한국어 상징어의 통사.의미론적 연구) [Características sintácticas y semánticas de las mímesis coreanas]. Aesanbakbo 애산학보 17. https://www.earticle.net/Journal/ Issues/441/4787

KIM, Hye-Jeoung. 2011. Coreano para principiantes. Salamanca: Universidad de Salamanca.

KIM, In-Hwa. 1995. "Hyeondae hangugeoui eumseongsangjingeo yeongu" 현대 한국어의 음성상징어 연구 [Estudio de las mímesis coreanas contemporáneas]. Tesis de doctorado. Ewha Womans University. https://academic.naver.com/article. naver?doc id $=11609579$

Kwon, Insook. 2014. "It all Leads to Education: Korean Motherhood, Patriarchy, and Class Consciousness in the TV Drama, Eligible Wife (Anaeui Jagyeok)". The Review of Korean Studies 17 (1): 39-70. https://www.kci.go.kr/kciportal/ci/ sereArticleSearch/ciSereArtiView.kci?sereArticleSearchBean. artiId $=$ ART001883215

LEE, Sang-Gyoo. 1993. "Gugeoui uiseong-uitaeeo yeongu” 국어 의 의성 의태어 연구 [Estudio de los ideófonos y las onomatopeyas coreanas]. Tesis de maestría. Universidad Hanyang. https://lib.aks.ac.kr/search/DetailView.ax?cid=19170

Müller, Max. 1861. Lectures on the Science of Language: Delivered at the Royal Institution of Great Britain in April, May, and June 1861. Londres: Longman, Green, Longman, y Roberts. https:// doi.org/10.1037/14263-000

Noss, Philip A. 2001. "Ideas, Phones, and Gbaya Verbal Art". En Ideophones, editado por F. K. Erhard Voeltz y Christa 
Kilian-Hatz, 259-270. Amsterdam: John Benjamins. https://doi. org $/ 10.1075 /$ tsl.44.21nos

Nuckolls, Janis B. 1999. “The Case for Sound Symbolism”. Annual Review of Anthropology 28: 225-252. https://doi.org/10.1146/ annurev.anthro.28.1.225

Nuckolls, Janis B. 2001. "Ideophones in Pastaza Quechua". En Ideophones, editado por F. K. Erhard Voeltz y Christa KilianHatz, 271-285. Amsterdam: John Benjamins. https://doi. org/10.1075/tsl.44.22nuc

NucKOLls, Janis B. 2006. “The Neglected Poetics of Ideophony”. En Language, Culture and the Individual: A Tribute to Paul Friedrich, editado por Catherine O’Neil, Mary Scoggin y Kevin Tuite, 39-50. Múnich: Lincom Europa.

PARK, Dong-Geun. 1996. "Hyeondaegugeo hyungnaemarui yeongu" 현대국어 흥내말의 연구 [Un estudio de las palabras simbólicas en coreano moderno]. Tesis de doctorado. Konkuk University. https://academic.naver.com/article.naver?doc_id $=11620313$

PARK, Dong-Geun. 2008. "Hangugeo hyungnaemarui ihae" 한국어 흥내말의 이해 [Comprensión de las mímesis coreanas]. Seúl: Yeongnak.

PARK, Dong-Geun. 2016. "Hangugeo uiseongeowa uitaeeoui hyeongtae bigyo" 한국어 의성어와 의태어의 형태 비교 [Una comparación morfológica entre palabras onomatopéyicas e imitativas del coreano]. Hanmaryeongubakoe 한말연구학회 Korean Language Research, núm. 42, 61-82. https://doi.org/10.16876/ klrc.2016.42.61

PARK, Min-Gyu. 2012. Kaseutera 카스테라 [Bizcocho]. Seúl: Munhakdongne.

Schourup, Lawrence. 1993. "Nichi-Ei Onomatope no Taisho: KenKyu" [Un estudio contrastivo de la onomatopeya japonesa e inglesa]. Gengo 22 (6): 48-55.

URTEL, Herman. 1919. “Zur baskischen Onomatopoesis”. Berlin: n.d. Voeltz, F. K. Erhard y Christa Kilian-Hatz, eds. 2001. Ideophones. Amsterdam: John Benjamins. https://doi.org/10.1075/tsl.44

WojCIECHOwski, Bartosz T. 2013. "Japanese Ideophones: Towards a Systematic Phono-Semantic Description”. Silva Iaponicarum, núm. 35-36, 27-45. 
Cristina Bahón Arnaiz finalizó su doctorado en lingüística coreana y traducción literaria coreano-español en octubre de 2019. En 2018, se incorporó al Literature Translation Institute of Korea, donde desde hace más de dos años investiga sobre la traducción literaria, películas y webtoons coreano-español. En este periodo ha realizado diferentes estudios acerca del uso de ideófonos en la literatura, webtoons, artículos de periódico y redes sociales. Además, trabaja como traductora para Toomics, una empresa coreana de webtoons.

https://orcid.org/0000-0002-3090-9130 phd.cristinabahon@gmail.com 